\title{
Dieta alcalina: Alegações apresentadas na literatura para saúde e tratamento de doenças
}

\author{
Alkaline diet: Allegations presented in literature for health and disease treatment \\ Dieta alcalina: Reclamaciones presentadas en literatura para tratamiento de salud y \\ enfermedad
}

Ana Lúcia Munaro Tacca Hohl, Antonio Márcio Teodoro Cordeiro Silva

\begin{abstract}
RESUMO
Objetivo: Avaliar, por meio da literatura científica disponível, as alegações para utilização ou não de dietas classificadas como alcalinas, seus fundamentos e evidências. Métodos: Trata-se de uma revisão de literatura por meio da qual foram analisadas publicações identificadas nas bases de dados PubMed e Biblioteca Virtual em Saúde. A busca foi realizada utilizando os descritores "dieta alcalina", "água alcalina", "equilíbrio ácidobase", "pH". Resultados: Diversos estudos têm sugerido que uma dieta alcalina pode prevenir e tratar várias doenças e resultar em benefícios para a saúde, provenientes da alcalinização corporal. Foram selecionados estudos relacionados à dieta alcalina e alegação de saúde ou condição patológica específica. Além da leitura dos artigos científicos, foi realizada pesquisa em livros e sites relacionados. Considerações finais: Não há consenso para a aplicação da dieta alcalina nas situações estudadas e, por isso, a teoria não se sustenta cientificamente até o momento. Apesar disso, é evidente que a adoção de hábitos alimentares que proporcionem um padrão alimentar mais saudável, com maior oferta de fibras e alimentos in natura e menor ingestão de gorduras, alimentos industrializados ricos em sódio e carboidratos simples, traz inúmeros benefícios que não podem ser atribuídos apenas à teoria da dieta alcalina.
\end{abstract}

Palavras-chave: Dieta, Água alcalina, Equilíbrio ácido-base, pH.

\begin{abstract}
Objective: To evaluate, through the available scientific literature, the claims for use or not of diets classified as alkaline, their grounds and evidence. Methods: This is a literature review through which publications identified in the PubMed and Virtual Health Library databases were analyzed. The search was performed using the descriptors "alkaline diet", "alkaline water", "acid- base"," pH ". Results: Several studies have suggested that an alkaline diet can prevent and treat various diseases and result in health benefits from bodily alkalinization. Studies related to alkaline diet and health claim or specific pathological conditions were selected. In addition to reading the scientific articles, research was conducted on books and related websites. Final considerations: There is no consensus for the application of alkaline diet in the studied situations and, therefore, the theory is not scientifically supported so far. Nonetheless, it is evident that the adoption of eating habits that provide a healthier eating pattern, with a higher supply of fiber and fresh foods and a lower intake of fat, sodium-rich processed foods and simple carbohydrates, has numerous benefits that cannot be achieved attributed only to the alkaline diet theory.
\end{abstract}

Keywords: Diet, Alkaline water, Acid-base balance, $\mathrm{pH}$.

1Pontifícia Universidade Católica de Goiás, Goiânia, Goiás. *E-mail: munaro.analucia@gmail.com

SUBMETIDO EM: 9/2019

ACEITO EM: 10/2019

PUBLICADO EM: 11/2019

REAS/EJCH | Vol.Sup.36 | e1706 | DOI: https://doi.org/10.25248/reas.e1706.2019 Página 1 de 8 


\section{RESUMEN}

Objetivo: Evaluar, a través de la literatura científica disponible, las afirmaciones de uso o no de dietas clasificadas como alcalinas, sus fundamentos y evidencia. Métodos: Esta es una revisión de la literatura a través de la cual se analizaron las publicaciones identificadas en las bases de datos de PubMed y Virtual Health Library. La búsqueda se realizó utilizando los descriptores "dieta alcalina", "agua alcalina", " base "," pH". Resultados: Varios estudios han sugerido que una dieta alcalina puede prevenir y tratar diversas enfermedades y generar beneficios para la salud de la alcalinización corporal. Se seleccionaron estudios relacionados con la dieta alcalina y el reclamo de salud o condición patológica específica. Además de leer los artículos científicos, se realizaron investigaciones en libros y sitios web relacionados. Consideraciones finales: No hay consenso para la aplicación de la dieta alcalina en las situaciones estudiadas y, por lo tanto, la teoría no está respaldada científicamente hasta ahora. Sin embargo, es evidente que la adopción de hábitos alimenticios que proporcionan un patrón de alimentación más saludable, con un mayor suministro de fibra y alimentos frescos y una menor ingesta de grasas, alimentos procesados ricos en sodio y carbohidratos simples, tiene numerosos beneficios que no se pueden lograr atribuido solo a la teoría de la dieta alcalina.

Descriptores: Dieta, Agua alcalina, Equilibrio ácido-base, pH.

\section{INTRODUÇÃO}

Nas últimas décadas, as mudanças no comportamento e no padrão alimentar da população tem levado a uma dieta caracterizada pela alta ingestão de alimentos processados, proteína animal e carboidratos refinados, combinada com a ingestão, muitas vezes, insuficiente, de frutas e vegetais (KOZAN P et al., 2017). O trabalho da mulher fora do lar, a maior praticidade, rapidez, durabilidade e boa aceitação dos produtos industrializados contribuem para esta mudança nos hábitos das famílias (BORTOLINI GA et al., 2012).

Dentre os problemas nutricionais causados pela mudança no padrão alimentar, destaca-se o elevado consumo de alimentos processados e ultraprocessados. A preferência por produtos industrializados em detrimento de preparações caseiras favorece o aumento da densidade energética da dieta devido ao perfil nutricional desfavorável destes alimentos, normalmente produzidos com altos teores de açúcar, gordura saturada e de gordura trans e, ainda, pobre em fibras e potássio, impactando negativamente na qualidade da alimentação (LOUZADA MLC et al., 2015).

O padrão alimentar acima descrito prejudica o balanço energético e favorece o excesso de peso e a obesidade, assim como o excesso de gorduras saturadas e a presença de gordura trans, aumentam a morbimortalidade por doenças cardiovasculares. Adicionalmente, a ingestão insuficiente de fibras além de favorecer a obesidade, potencializa o risco de doenças crônicas não transmissíveis, como diabetes, doenças cardiovasculares e vários tipos de câncer, como de cólon e reto e de mama (LOUZADA MLC et al., 2015).

As proteínas de origem animal são ricas em aminoácidos que contêm enxofre, como a cisteína e metionina. Estes, quando metabolizados, levam à produção de ácidos não voláteis, como o ácido clorídrico e sulfato de hidrogênio, o que torna a dieta ocidental "acidogênica" (KOZAN P et al., 2017). Tem sido sugerido que uma dieta alcalina, rica em frutas e vegetais e reduzida em proteínas animais, pode prevenir várias doenças e resultar em benefícios significativos para a saúde (SCHWALFENBERG GK, 2012).

Assim, diversos estudos têm avaliado a hipótese de que uma dieta de padrão alcalino seria benéfica para a saúde, contribuindo tanto para a prevenção, como para o tratamento de doenças, tais como a osteoporose, câncer, doença renal crônica e diabetes (KOZAN P et al., 2017; FENTON TR et al., 2009; ASTIGIANO S et al., 2017; ANGÉLOCO LRN et al., 2017; WILLIAMS RS et al., 2016).

Neste sentido, a mídia e a literatura leiga têm divulgado tais possíveis benefícios atribuídos à dieta alcalina, muitas vezes defendida por profissionais da área de saúde, aplicando esta teoria para as mais diversas situações, especialmente no tratamento de doenças (SCHWALFENBERG GK, 2012; HUEBNER J et al., 2014). Em contrapartida, o Instituto Americano de Pesquisas sobre o Câncer (AICR), garante que essas 
afirmações contrastam com tudo o que a ciência mostra sobre a bioquímica do corpo humano e que o equilíbrio ácido-base é rigidamente regulado por vários mecanismos autossuficientes (AICR, 2018).

Diante de apontamentos controversos, o presente estudo objetivou revisar e reunir a literatura científica disponível acerca do tema com a finalidade de avaliar as principais hipóteses levantadas e a coerência de cada uma delas.

\section{MÉTODOS}

Este estudo trata-se de uma revisão de literatura para reunir estudos sobre a relação entre a dieta alcalina e as alegações de benefícios à saúde, assim como a relação entre diversas doenças e seus tratamentos por meio do direcionamento alimentar para o chamado perfil alcalino. Foram analisadas publicações identificadas nas bases de dados PubMed e Biblioteca Virtual em Saúde (BVS). A busca foi realizada em março de 2018 e definiu-se a estratégia de busca livre, utilizando os descritores: dieta alcalina; água alcalina; equilíbrio ácidobase; $\mathrm{pH}$ (potencial hidrogeniônico).

Foram aplicados critérios de inclusão e exclusão para determinar a elegibilidade dos estudos. Como critérios de inclusão foram considerados: estudos disponíveis na íntegra, publicados no período de 2007 a 2018, que abordavam o tema proposto, em idioma inglês, espanhol ou português.

Como critérios de exclusão foram removidos: textos incompletos, trabalhos de conclusão de curso, dissertações e teses, artigos científicos que não abordavam o tema, publicados em anos anteriores a 2007, em outros idiomas que não os considerados.

As referências recuperadas nas buscas foram avaliadas com base nos títulos e resumos ordenados por ano de publicação.

\section{RESULTADOS E DISCUSSÃO}

\section{Equilíbrio ácido-base}

Os valores de normalidade para o pH do sangue arterial vão de 7,35 a 7,45 e a manutenção do pH dentro dessa faixa é essencial para o adequado funcionamento de diversas reações bioquímicas (CHARNEY P, 2012). A manutenção corporal adequada de água e eletrólitos é fundamental para esse equilíbrio, assim como a concentração de íons $\mathrm{H}^{+}$, de ácidos e bases. Esse equilíbrio químico entre as bases e os ácidos é denominado equilíbrio ácido-básico (SILVA MLT et al., 2017).

O equilíbrio ácido-base é rigidamente regulado por vários mecanismos, entre eles estão, principalmente, as funções renais e respiratórias e, pequenas mudanças no $\mathrm{pH}$ do corpo, são eventos importantes e devem ser considerados como risco à vida. Pacientes com doença renal e disfunção pulmonar, por exemplo, muitas vezes dependem de máquinas de diálise e ventiladores mecânicos para evitar ou corrigir até mesmo pequenas perturbações do equilíbrio ácido-base (AICR, 2018).

O teste de gasometria arterial, traz, dentre outros parâmetros, o valor do $\mathrm{pH}$ arterial. Valores de $\mathrm{pH}$ abaixo de 7,35 indicam acidose e são caracterizados pelo aumento de íons $\mathrm{H}^{+}$no sangue, enquanto valores de $\mathrm{pH}$ acima de 7,45 indicam alcalose e são caracterizados pela redução dos íons $\mathrm{H}^{+}$no sangue. Assim, pode-se afirmar que o estado de acidose metabólica é resultado do desequilíbrio causado pelo acúmulo de ácido não excretado ou pela perda de bases. Já a alcalose metabólica é a situação contrária, onde há acúmulo de bases ou perdas excessivas de íons $\mathrm{H}^{+}$(SILVA MLT et al., 2017). A avaliação correta do equilíbrio ácido-base deve levar em consideração os parâmetros da gasometria arterial e os valores dos eletrólitos séricos e sua etiologia pode ser diferenciada em metabólica ou respiratória (CHARNEY P, 2012).

Estados de acidose metabólica grave intensificam o catabolismo protéico, pois aceleram a proteólise e reduzem a síntese de proteínas. Em pacientes portadores de doenças que evoluem para estado catabólico, a acidose pode interferir diretamente no prognóstico, acelerando essa condição. Já a alcalose metabólica apresenta menor gravidade e é de mais fácil controle quando identificada a causa (SILVA MLT et al., 2017). 
Foram selecionados estudos que relacionavam a dieta alcalina a alguma alegação de saúde ou a alguma condição patológica específica, sendo excluídos aqueles de caráter apenas físico-químico ou ainda aqueles que realizaram experimentos em animais não mamíferos. Para compor todo o referencial teórico, além da leitura dos artigos científicos, foi realizada pesquisa em livros e sites relacionados. Para compor a narrativa, os estudos foram agrupados de acordo com a temática abordada (Quadro 1).

Quadro 1 - Artigos incluídos na presente revisão, 2019.

\begin{tabular}{|c|c|c|}
\hline Autor & Idioma & Objetivo do trabalho \\
\hline Welch AA, et al. (2007) & Inglês & $\begin{array}{l}\text { Investigar a relação entre o pH urinário e a carga ácido-base da } \\
\text { dieta e a contribuição dos grupos de alimentos. }\end{array}$ \\
\hline Fenton TR, et al. (2009) & Inglês & $\begin{array}{l}\text { Avaliar as variações da excreção de cálcio na urina pela } \\
\text { manipulação da ingestão ácido-base em adultos saudáveis. }\end{array}$ \\
\hline Fenton TR, et al. (2009) & Inglês & $\begin{array}{l}\text { Avaliar a contribuição do fosfato da dieta na saúde óssea e } \\
\text { secundariamente, avaliar, se esses efeitos são alterados pelo } \\
\text { nível de ingestão de cálcio. }\end{array}$ \\
\hline Fenton TR, et al. (2010) & Inglês & $\begin{array}{l}\text { Determinar se o baixo pH urinário ou a excreção ácida na urina } \\
\text { são preditores para fraturas por fragilidade e/ou mudança em } \\
\text { cinco anos da densidade mineral óssea em adultos. }\end{array}$ \\
\hline Fenton TR, et al. (2011) & Inglês & $\begin{array}{l}\text { Avaliar as relações causais entre carga de ácido dietético e } \\
\text { osteoporose usando os critérios de Hill (temporalidade; força da } \\
\text { associação; gradiente biológico; plausibilidade biológica; } \\
\text { consistência; evidências experimentais). }\end{array}$ \\
\hline Schwalfenberg GK (2011) & Inglês & Avaliar as evidências encontradas na literatura científica. \\
\hline $\begin{array}{l}\text { Hanley DA e Whiting SJ } \\
\text { (2013) }\end{array}$ & Inglês & $\begin{array}{l}\text { Examinar os diferentes tipos de evidência para o efeito ácido- } \\
\text { básico na saúde óssea e fornecer recomendações para ingestão } \\
\text { dietética que estejam alinhadas com as evidências. }\end{array}$ \\
\hline Huebner J, et al. (2014) & Inglês & $\begin{array}{l}\text { Informar sobre dietas contra o câncer aos médicos e outros } \\
\text { profissionais de saúde e trazer recomendações sobre como } \\
\text { discutir as dietas do câncer com os pacientes, a fim de apoiar a } \\
\text { tomada de decisões compartilhada baseada em evidências. }\end{array}$ \\
\hline Caciano S, et al. (2015) & Inglês & $\begin{array}{l}\text { Avaliar a hipótese de que uma dieta de baixo PRAL (potencial de } \\
\text { carga ácida renal) de curto prazo (4-9 dias) resulta em maior taxa } \\
\text { de troca respiratória durante o exercício máximo em comparação } \\
\text { àquela após uma dieta com alto PRAL. Um segundo objetivo do } \\
\text { estudo foi determinar se uma dieta com baixo PRAL melhora o } \\
\text { desempenho do exercício anaeróbico. }\end{array}$ \\
\hline $\begin{array}{l}\text { Fenton TR e Huang T } \\
\text { (2016) }\end{array}$ & Inglês & $\begin{array}{l}\text { Determinar se existe evidência de uma relação causal entre ácido } \\
\text { dietético ou alcalino e a etiologia do câncer e/ou o tratamento } \\
\text { desta doença. }\end{array}$ \\
\hline Mousa AH (2016) & Inglês & $\begin{array}{l}\text { Investigar o uso da dieta alcalina e água alcalina e do contato com } \\
\text { o meio natural de promoção da saúde e prevenção de doenças } \\
\text { crônicas. }\end{array}$ \\
\hline Williams RS, et al. (2016) & Inglês & $\begin{array}{l}\text { Explorar o papel da carga de ácido dietético e acidose metabólica } \\
\text { leve na resistência à insulina e diabetes tipo } 2 \text {. }\end{array}$ \\
\hline Passey C (2017) & Inglês & $\begin{array}{l}\text { Avaliar se a redução da carga ácida da dieta, com redução de } \\
\text { proteínas e aumento de vegetais e frutas retardariam a doença } \\
\text { ou melhoraria a função renal dos indivíduos avaliados. }\end{array}$ \\
\hline Astigiano S, et al (2017) & Inglês & $\begin{array}{l}\text { Avaliar a progressão de tumores de próstata em ratos submetidos } \\
\text { à alcalinização por meio de água alcalina. }\end{array}$ \\
\hline Kozan P (2017) & Inglês & $\begin{array}{l}\text { Investigar se o tamponamento de uma refeição de alta carga } \\
\text { ácida com um tratamento alcalinizante muda o metabolismo da } \\
\text { glicose pós-refeição. }\end{array}$ \\
\hline Angéloco LR (2017) & Inglês & $\begin{array}{l}\text { Discutir os aspectos dietéticos relacionados ao equilíbrio ácido- } \\
\text { básico na acidose metabólica de doentes renais crônicos. } \\
\text { Fornecer possíveis estratégias para o manejo nutricional nesses } \\
\text { casos. }\end{array}$ \\
\hline
\end{tabular}

Fonte: Hohl ALMT e Silva AMTC, 2019. 
Os ácidos podem ser produzidos por via endógena ou introduzidos por via exógena. Endogenamente, a produção de ácidos acontece por diversos mecanismos tissulares normais e, exógenamente, os ácidos podem ser introduzidos via consumo de alimentos precursores de ácidos e toxinas (CHARNEY P, 2012). Dentre as bases, estão os fosfatos e o bicarbonato, sendo este último o principal, formado pela combinação do dióxido de carbono com água, por meio do metabolismo celular (SILVA MLT et al., 2017).

A regulação deste equilíbrio depende da função pulmonar e renal, por meio da retenção ou eliminação dos principais componentes desta equação que são o dióxido de carbono, o hidrogênio e o bicarbonato (SILVA MLT et al., 2017).

\section{Alimentos como influenciadores do estado ácido-básico}

No geral, dentre os grupos de alimentos, as proteínas são a principal fonte de carga ácida na dieta, principalmente aminoácidos contendo enxofre, como a metionina e a cisteína. Já os alimentos mais alcalinos são aqueles de origem vegetal, principalmente aqueles ricos em micronutrientes alcalinizantes, como o cálcio, o potássio e o magnésio (DEAN S, 2012).

Dean S (2012) propõe uma lista de alimentos e seu potencial para influenciar a carga ácida renal. Dentre os alimentos potencialmente acídicos estão: as proteínas, especialmente as de origem animal, como carne vermelha, peixes, aves, mariscos, ovos e queijos; as gorduras provenientes de alimentos como bacon, nozes, semente de abóbora e girassol, molhos para saladas cremosos; as fontes de carboidratos como pães, farelo de milho e arroz, aveia, macarrão, centeio e trigo; os doces, principalmente os produzidos industrialmente, como as misturas instantâneas. Quanto aos alimentos potencialmente alcalinizantes estão frutas, vegetais e temperos naturais, além de castanhas, café, açúcar marrom, melaço e cacau em pó. Há ainda os alimentos neutros como as gorduras provenientes da manteiga, margarina e óleos; laticínios; milho; açúcar branco, maioria dos xaropes, mel e bebidas, como água, chás.

Welch AA et al., (2008) investigaram a relação entre o pH urinário, a carga ácido-base da dieta e a contribuição dos grupos de alimentos, e concluíram que a dieta mais alcalina, com alto consumo de frutas e vegetais e baixo consumo de carnes foi significativamente associada com $\mathrm{pH}$ urinário mais alcalino.

\section{Alegações de saúde - dieta alcalina}

A literatura selecionada aborda diversas alegações de saúde para a dieta alcalina, dentre elas os benefícios para a saúde óssea, a saúde renal, redução de doenças crônicas, como o diabetes e o tratamento ou retardo da evolução do câncer (FENTON TR et al., 2009; PASSEY C, 2017; ASTIGIANO S et al., 2017 ).

\section{Dieta alcalina e saúde óssea}

Essa hipótese considera que a dieta moderna leva à osteoporose ou ao enfraquecimento ósseo por meio da produção de ácido proveniente do metabolismo de proteínas e grãos e que o processo de tamponamento ácido requer mobilização de mineral ósseo, resultando em cálcio perdido na urina, em processo espoliativo. A hipótese sugere também que frutas e legumes fornecem um suprimento de moléculas orgânicas que são metabolizadas em bicarbonato e, portanto, protegem o tecido esquelético. Especificamente, a hipótese afirma que alimentos ou fontes suplementares de ânions (referido como precursores ácidos), fosfato ( $\mathrm{PO}^{-}{ }^{-}$), sulfato (SO4), cloreto $\left(\mathrm{Cl}^{-}\right)$, e ácidos orgânicos, causam acidose metabólica e aumentam a calciúria quando consumida em excesso, o que é prejudicial à saúde óssea. Já fontes alimentares ou suplementos de cátions (referidos como precursores alcalinos ou bases), sódio, potássio, cálcioe magnésio, diminuiriam a calciúria e teriam efeito protetor sobre o osso (FENTON TR et al., 2009).

Quanto às doenças ósseas, Fenton TR et al. (2009); Fenton TR et al. (2011), em seus estudos, concluíram que a dieta alcalina não influencia de forma positiva para a manutenção da saúde óssea, redução de fraturas, redução dos riscos da osteoporose. Portanto, para esta finalidade, a hipótese da dieta alcalina não se justifica. No mesmo sentido, Schwalfenberg GK (2012) conclui que apesar das dietas alcalinas resultarem em pH mais alcalino da urina e poder contribuir com a redução de cálcio na urina, isso pode não refletir o equilíbrio de cálcio total e não há evidências substanciais de que isso melhore a saúde óssea ou previna a osteoporose. 
Hanley DA e Whiting SJ (2013) concordam que não há evidências suficientes para apoiar uma relação causal entre a composição ácido/alcalino de uma dieta e saúde óssea, no entanto, ressaltam o benefícioproporcionado por uma dieta saudável, com o aumento de vegetais e conteúdo de frutas ou suplementos contendo bicarbonato de potássio ou citrato.

\section{Dieta alcalina e câncer}

Em diversas condições de saúde, os pacientes procuram métodos alternativos para tratamento, como no caso dos cânceres, por exemplo. Muitos pacientes com câncer usam métodos complementares e medicina alternativa. Neste contexto, dietas e suplementos nutricionais são comumente citados. Por meio destes, os pacientes buscam meios para fortalecer o sistema imunológico. Intuitivamente, mudanças na dieta e consumo de suplementos são as maneiras mais comuns de incluir substâncias que aparentemente apresentam-se em carência. Neste cenário, diversas fórmulas e dietas são sugeridas pelas mídias ou por outros meios. Diante disso, é importante avaliar detalhadamente cada teoria, para que o paciente possa receber informações precisas e cientificamente comprovadas do benefício das mesmas (HUEBNER $J$ et al., 2014).

No caso do câncer, a hipótese é de que alimentos ácidos podem alterar o equilíbrio do pH do corpo e favorecer o câncer. Isso porque estudos in vitro sugeriram que as células tumorais se desenvolvem em um ambiente ácido, mas não conseguem o mesmo efeito de sobrevivência e proliferação em ambientes alcalinos (AICR, 2018). Astigiano S et al (2017), em estudo com camundongos,encontraram relação positiva entre a dieta alcalina e o câncer, correlacionando efeitos redutores na progressão de tumores nestes animais, sugerindo portanto, que a alcalinização do microambiente tem efeito profilático na progressão de alguns tumores de próstata. Entretanto, Fenton TR e Huang T (2016); Fenton TR e Fenton CJ (2016) consideraram que, apesar da divulgação e promoção da dieta alcalina e da água alcalina pelos meios de comunicação e vendedores, quase não há pesquisas reais que justifiquem o seu uso.

\section{Dieta alcalina e as doenças renais}

Nas doenças renais, a hipótese se desenvolve a partir o conhecimento de que o aumento do consumo de frutas e legumes reduz os danos nos rins e retarda a progressão da doença renal crônica (DRC) (PASSEY C, 2017). Segundo Angéloco LRN, et al. (2017), uma dieta com teor protéico reduzido $(0,6$ a $0,8 \mathrm{~g} / \mathrm{kg} / \mathrm{dia})$, associada ao aumento no consumo de frutas e vegetais pode reduzir a quantidade de íons de hidrogênio no corpo e, por isso, poderia melhorar o metabolismo e os parâmetros de acidose, favorecendo a redução de danos renais e mesmo a progressão da DRC.

Passey C (2017) concluiu que os pacientes relataram se sentir melhor com a dieta adaptada com baixa proteína. O maior consumo de proteína de origem vegetal, de frutas e verduras, reduziria a ingestão de ácido dietético e, consequentemente, a quantidade de ácido a ser neutralizado pelos rins, o que reduziria os possíveis danos renais e poderia retardar a progressão da DRC. Além disso, sugere também que este padrão dietético poderia ajudar a preservar a massa muscular e os ossos.

\section{Dieta alcalina e demais alegações encontradas}

Além das alegações de benefícios já relatadas, outros estudos abordam a mesma temática em outras situações, tais como, desempenho no exercício físico, promoção da saúde, prevenção de doenças crônicas,resistência à insulina, diabetes tipo 2 e nas taxas de glicemia pós-prandial (KOZAN P et al., 2017; WILLIAMS RS et al., 2016; CACIANO S et al., 2015; MOUSA AH, 2016). Caciano $S$ et al. (2015) observaram alterações de curto prazo na dieta com o objetivo de avaliar o desempenho físico nesta situação. Seu estudo concluiu que diminuir a carga de ácido sistêmico, por meio da dieta, não eleva a taxa de troca respiratória máxima no exercício, podendo até mesmo reduzi-la. Seu estudo mostrou ainda que uma dieta considerada de promoção alcalina, ou seja, rica em frutas e vegetais e pobre em carnes e grãos, melhoraria o desempenho do exercício anaeróbico em $21 \%$.

Dentre as variáveis estudadas por Mousa AH (2016), efeitos benéficos para a saúde podem ser obtidos com o consumo de dietas alcalinas, que são ricas em frutas e vegetais, assim como consumir água mineral alcalina. 
Quanto à resistência à insulina e ao diabetes tipo 2, há a hipótese de que a acidose metabólica induz a resistência à insulina no músculo esquelético para permitir a degradação de proteínas e gerar a amônia necessária para promover a excreção de íons de hidrogênio, resultando em um risco aumentado para o diabetes tipo 2, além de sugerir que a acidose pode induzir a produção de glicocorticoides e, o aumento resultante no cortisol plasmático pode, por sua vez, contribuir para a resistência à insulina e proteólise. Entretanto, permanece desconhecido se uma dieta de padrão alcalino pode reduzir a acidose metabólica, melhorar a sensibilidade à insulina e reduzir o risco de diabetes (WILLIAMS RS et al., 2016).

Ainda sobre o metabolismo da glicose, Kozan P et al. (2017) avaliaram se o tamponamento de uma refeição rica em alimentos de elevada carga ácida com um tratamento alcalinizante, mudaria o metabolismo da glicose pós-prandial. A conclusão foi de que uma substância considerada alcalinizante administrada prérefeição não tem efeito agudo na glicemia e na resposta insulínica em indivíduos saudáveis e, portanto, a hipótese foi negada.

\section{CONSIDERAÇÕES FINAIS}

A aplicação da dieta alcalina nas situações estudadas não está completamente elucidada e não se sustenta cientificamente até o momento. Apesar disso, é evidente que a adoção de hábitos alimentares que proporcionem melhoria do padrão alimentar, tornando-o mais saudável, com maior oferta de fibras e alimentos in natura e menor consumo de gorduras, alimentos industrializados ricos em sódio e carboidratos simples, trazem inúmeros benefícios e que estes, por sua vez, não podem ser atribuídos isoladamente à teoria da dieta alcalina. Por fim, mais estudos sobre o assunto são necessários para elucidar a influência direta da alimentação no $\mathrm{pH}$ corporal e seus desdobramentos. O que já está bem fundamentado é que o conjunto de aspectos que envolvem estilo de vida e alimentação adequada e equilibrada são fatores primordiais para a manutenção da saúde ou prevenção de doenças.

\section{REFERÊNCIAS}

1. AICR - American Institute for Cancer Research. Alkaline Diets. Disponível em: http://www.aicr.org/patientssurvivors/healthy-or-harmful/alkaline-diets.html. Aceso em 09/04/2018.

2. ANGÉLOCO LRN, et al. Alkaline diet and metabolic acidosis: pratical approaches to the nutritional management of chronic kidney disease. Journal of Renal Nutrition. 2017; 28(3): 215-220.

3. ASTIGIANO S, et al. Systemic alkalinisation delays prostate cancer cell progression in TRAMP mice. Journal of Enzyme Inhibition and Medicinal Chemistry. 2017; 32 (1): 363-368.

4. BORTOLINI GA et al. Consumo alimentar entre crianças brasileiras com idade de 6 a 59 meses. Caderno Saúde Pública. 2012; 28 (9): 1759-1771.

5. CACIANO S, et al. Effects of dietary acid load on exercise metabolism and anaerobic exercise performance. Journal of Sports Science and Medicine. 2015; 14: 364-71.

6. CHARNEY P. Clínico: água, eletrólitos e equilíbrio ácido-base. In: Mahan IK, Escott-Stump S, Raymond JL. Krause: Alimentos, Nutrição e Dietoterapia. 13 ed. Rio de Janeiro: Elsevier; 2012,p. 179-190.

7. DEAN S. pH urinário - Como a Dieta o Afeta? In: Mahan IK, Escott-Stump S, Raymond JL. Krause: Alimentos, Nutrição e Dietoterapia. 13 ed. Rio de Janeiro: Elsevier; 2012, p. 803.

8. FENTON T R e FENTON C J. Evidence does not support the alkaline diet. Osteoporosis International. 2016; 27(7): 2387-88.

9. FENTON T R e HUANG T. Systematic review of the association between dietary acid load, alkaline water and cancer. British Medical Journal Open. 2016; 6.

10. FENTON TR, et al. Phosphate decreases urine calcium and increases calcium balance: A meta-analysis of the osteoporosis acid-ash diet hypothesis. Nutrition Journal. 2009; 8(41).

11. FENTON TR et al. Low urine $\mathrm{pH}$ and acid excretion do not predict bone fractures or the loss of bone mineral density: a prospective cohort study. 2010; BMC Musculoskeletal Disorders. 11(88).

12. FENTON TR, et al. Meta-Analisys of the effect of the Acid-Ash Hypothesis of Osteoporosis on Calcium Balance. Journal of Bone and Mineral Research. 2009; 24(11): 1835-40.

13. FENTON TR, et al. Casual assessment of dietary acid load and bone disease: a systematic review and meta-analysis applying Hill's epidemiologic criteria for causality. Nutrition Journal. 2011; 10 (41). 
14. HANLEY DA e WHITING S J. Does a high dietary acid content cause bone loss, and can bone loss be prevented with an alkaline diet? Journal of Clinical Densitometry. 2013; 14 (4): 420-25.

15. HUEBNER J, et al. Counseling patients on cancer diets: a review of the literature and recommendations for clinical practice. Anticancer Research. 2014; 34: 39-48.

16. KOZAN $\mathrm{P}$, et al. The effect of buffering high acid load meal with sodium bicarbonate on postprandial glucose metabolism in humans-a randomized placebo-controlled study. Nutrients. 2017; 9 (861): 1-13.

17. LOUZADA MLC, et al. Alimentos ultraprocessados e perfil nutricional da dieta no Brasil. Revista de Saúde Pública. 2015; 49 (38): 1-11.

18. MOUSA A H. Health effects of alkaline diet and water, reduction of digestive-tract bacterial load, and earthing. Alternative Therapies in Health and Medicine.2016; 22 (1): 24-33.

19. PASSEY C. Reducing the dietary acid load: how a more alkaline diet benefits patients with chronic kidney disease. Journal of Renal Nutrition. 2017; 27 (3): 151-60.

20. SCHWALFENBERG GK. The alcaline diet: Is there evidence that an alkaline pH diet benefits health? Journal of Environmental Research and Public Health. 2012; doi: 10.1155/2012/727630.

21. SILVA MLT, et al. Alterações do Equilíbrio Acidobásico. In: Waitzberg D L. Nutrição Oral, Enteral e Parenteral na Prática Clínica. 5 ed. Rio de Janeiro: Atheneu; 2017,p. 255-270.

22. WELCH AA, et al. Urine $\mathrm{pH}$ is an indicator of dietary acid-base load, fruit and vegetables and meat intakes: results from the European Prospective Investigation in to Cancer and Nutrition (EPIC)-Norfolk population study. British Journal of Nutrition. 2008; 99: 1335-43.

23. WILLIAMS RS, et al. The role of dietary acid load and mild metabolic acidosis in insulin resistance in humans. Biochimie. 2016; 124: 171-177. 